\title{
Cross Reaction
}

National Cancer Institute

\section{Source}

National Cancer Institute. Cross Reaction. NCI Thesaurus. Code C96482.

A molecular interaction between a lig and molecule and a receptor molecule, where the lig and and receptor are not conventional partners. This interaction can occur because the lig and molecule shares structural features with the archetypal ligand. 